Chapman University

Chapman University Digital Commons

2-9-2021

\title{
Load Carriage Affects Kinematics during Ingress and Egress on Simulated Travelators
}

Alex Charbonneau

Ben Garson

Fiona Bisoffi

Stephanie Esparza

Miral Bhakta

See next page for additional authors

Follow this and additional works at: https://digitalcommons.chapman.edu/pt_articles

Part of the Physical Therapy Commons 


\section{Load Carriage Affects Kinematics during Ingress and Egress on Simulated Travelators}

\section{Comments}

This is a pre-copy-editing, author-produced PDF of an article accepted for publication in the Proceedings of the Human Factors and Ergonomics Society Annual Meeting in 2020. The definitive publisherauthenticated version is available online at https://doi.org/10.1177/1071181320641258.

\section{Creative Commons License}

(c) (i) (9)

This work is licensed under a Creative Commons Attribution-Noncommercial-No Derivative Works 4.0 License.

\section{Copyright}

The authors

\section{Authors}

Alex Charbonneau, Ben Garson, Fiona Bisoffi, Stephanie Esparza, Miral Bhakta, Luke Bailey, and Rahul Soangra 


\title{
Load Carriage affects Kinematics during Ingress and Egress on Simulated Travelators
}

\author{
Alexa Charbonneau ${ }^{1}$, Ben Garson ${ }^{1}$, Fiona Bisoffi ${ }^{1}$, Stephanie Esparza ${ }^{1}$, Miral Bhakta $^{1}$, Luke Bailey ${ }^{1}$, Rahul \\ Soangra $^{* 1} \& 2$ \\ ${ }^{1}$ Crean College of Health and Behavioral Sciences, Chapman University, Orange CA 92866 \\ ${ }^{2}$ Fowler School of Engineering, Chapman University, Orange CA 92866
}

\begin{abstract}
Technology advancements has impacted the quality of life in the modern world. Nowadays travelators found popularly as conveyers in airports have been widely used but it is not known how load carriage affects Ingress/egress on travelators. Ten healthy young adults stepped off a metal platform onto a forward moving treadmill belt at a given speed and then stepped on to a second platform. Data was collected to understand how load carriage could influence ingress and egress in participants. Participants were tested for four conditions (load, No load, speed of $0.3 \mathrm{~m} / \mathrm{s}$ and $0.6 \mathrm{~m} / \mathrm{s}$ ). Load carriage at speed $0.6 \mathrm{~m} / \mathrm{s}$ were found to have significantly higher knee flexion angles. Ankle angles measured for ingress presented different trends amongst the four conditions. Load carriage at speed $0.6 \mathrm{~m} / \mathrm{s}$ showed greater plantarflexion compared to the other three conditions. Our future work will assess effects of load carriage on travelators among older adults.
\end{abstract}

\section{Introduction}

In today's world travelling is an important part of our lives. Whether it be for a business trip or a family vacation, most people are often in a rush when they arrive at the airport to get through security and make it to the appropriate gate. There has been an influx of new technologies at larger airports, such as installed travelators, which are essentially moving platforms to get people across the airport faster than by simply walking. People have the choice to either walk on these moving platforms to make their walking speed faster or just let it take them across the airport at its own speed. Some travelators move faster up to $10 \mathrm{mph}$. for example: Travelators situated at Toronto Airport in Canada. The increased speed could increase fall risk for populations at risk, such as the elderly population, who are noticing muscle sarcopenia and a loss of fast twitch muscle fibers as they age(Lockhart, Smith, \& Woldstad, 2005) and obesity(Frames et al., 2018). In addition, falling has become prevalent enough that it is one of the top reasons for injury in many activities of daily living and occupational activities(Gialloreti \& Marazzi, 1996; Sekaran, Choi, Hayward, \& Langa, 2013). Clinically, it is important to look into environment and its interactions that could be contributing factor to the rising fall risk since early interventions could reduce injury in populations at risk. Often, these falls occur simply by a loss of balance, which would be an important factor in looking at travelators. By looking into gait kinematics in subjects on a travelator, we can determine if carrying a load (backpack) and walking on the travelator could be risky during traveling in some populations. We know that in general, external loads should lead to more difficulty maintaining balance, especially in certain placements such as unilateral loads(Walsh, Low, \& Arkesteijn, 2018). In this study, we tested subjects' ability to react to change in speed on this moving travelator with and without load carriage. We hypothesize that during load carriage participants will react more quickly during the process of ingress and egress with higher velocity, thus increased risk of fall. We also expect participants to exhibit higher angles of knee flexion and ankle dorsiflexion in ingress with load carriage.

\section{Methods \\ Subjects}

Ten subjects ( 5 males, 5 females) with no previous history of neurological disorders participated in this study. Their average age was $26 \pm 4$ years (average \pm SD), height was $162 \pm 9 \mathrm{~cm}$, and weight was $68 \pm 17 \mathrm{~kg}$. The protocol involved three trials for each condition for a subject. All subjects had to provide written consent as per Chapman University Institutional Review Board (CU-IRB).

\section{Equipment}

Twenty six infra-red markers were placed on the following bony landmarks: lateral malleolus, medial malleolus, calcaneus, 2nd distal phalanges of foot, 5th distal phalanges of foot, middle lateral leg, medial and lateral epicondyle of femur, middle lateral thigh, anterior superior iliac spine (ASIS), posterior superior iliac spine (PSIS), the twelfth thoracic vertebrae, xiphoid process, jugular notch, and the seventh cervical vertebrae. All participants used dominant limb (Right leg for everyone) as the leading limb. Motion of the participant was captured by several cameras set up at the GRAIL lab and processed using Vicon Nexus software. The sampling frequency for camera was set to $100 \mathrm{~Hz}$. Joint angles of the ankle, and knee were captured. Both knee angle and ankle angle were computed as per ISB recommendation.

\section{Experimental Protocol}

Participants were asked to step off of a metal platform elevated four inches from the height of a treadmill moving forward at a given speed and then step onto another platform at the end of the treadmill (Fig. 1). Each participant was placed in a harness to reduce fall risk and underwent 3 trials of 4 randomly ordered conditions to limit the learning effect (Hariton \& Locascio, 2018). Conditions were as follows: 1) No Load at $0.3 \mathrm{~m} / \mathrm{s}, 2)$ No Load at $0.6 \mathrm{~m} / \mathrm{s}, 3) 10 \%$ body- 
weight loaded pack on thoracic spine at $0.6 \mathrm{~m} / \mathrm{s}, 4) 10 \%$ bodyweight at $0.3 \mathrm{~m} / \mathrm{s}$.

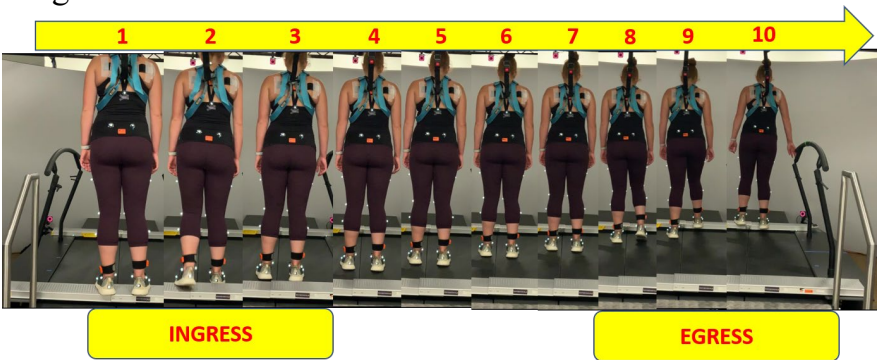

Figure 1. Ingress and Egress postural transitions on forward moving belt treadmill.

\section{Results}

The ingress time was computed as the elapsed time between when the subjects removed their first foot from the static platform and placed it onto the moving belt of the treadmill. The egress time was computed as the elapsed time between when the subjects removed their last foot from the treadmill and placed it onto the opposite platform. Thus, ingress and egress times evaluate the subjects' instability from static to dynamic or dynamic to static transition (Fig. 2). The mean ingress time without the load was $0.441(\mp 0.015)$ seconds at $0.3 \mathrm{~m} / \mathrm{s}$ and 0.423 ( $\mp 0.012$ ) seconds at $0.6 \mathrm{~m} / \mathrm{s}$. The mean ingress time with the load was $0.428(\mp 0.016)$ seconds at 0.3 $\mathrm{m} / \mathrm{s}$ and $0.412(\mp 0.014)$ seconds at $0.6 \mathrm{~m} / \mathrm{s}$. The mean egress time without the load was $0.443(\mp 0.018)$ seconds at $0.3 \mathrm{~m} / \mathrm{s}$ and $0.422(\mp 0.038)$ seconds at $0.6 \mathrm{~m} / \mathrm{s}$. Finally, the mean egress time with the load was 0.448 ( $\mp 0.018$ ) seconds at 0.3 $\mathrm{m} / \mathrm{s}$ and $0.388(\mp 0.017)$ seconds at $0.6 \mathrm{~m} / \mathrm{s}$.

Figure 3 depicts ingress knee flexion angles over time. All four conditions show a high knee flexion angle. Trials performed with no load at $0.3 \mathrm{~m} / \mathrm{s}$ and $0.6 \mathrm{~m} / \mathrm{s}$ had higher flexion at 47 degrees and 42 degrees respectively, compared to trials with a load. The condition of load at speed $0.3 \mathrm{~m} / \mathrm{s} \mathrm{had}$ highest knee flexion angle at 39 degrees and load at speed 0.6 $\mathrm{m} / \mathrm{s}$ highest knee flexion angle at 32 degrees. Whereas, the knee angles measured for egress showed high knee flexion when stepping off of the moving treadmill and onto a platform (Fig. 4). No load at speed $0.3 \mathrm{~m} / \mathrm{s}$ had the least amount of knee flexion at an angle of 33 degrees. Load at speed $0.3 \mathrm{~m} / \mathrm{s}$ and no load at $0.6 \mathrm{~m} / \mathrm{s}$ depicted the highest knee angle at 40 degrees. Load at speed $0.6 \mathrm{~m} / \mathrm{s}$ had a maximum knee flexion at 38 degrees. Fig. 5 and 6 illustrate the amount of ankle dorsiflexion and plantarflexion during ingress and egress processes, respectively. At 90 degrees the ankle is in a neutral position, any greater value indicates plantarflexion and any lesser value indicates dorsiflexion. All angles shown in figures $3,4,5$ and 6 are averages of 10 participants.

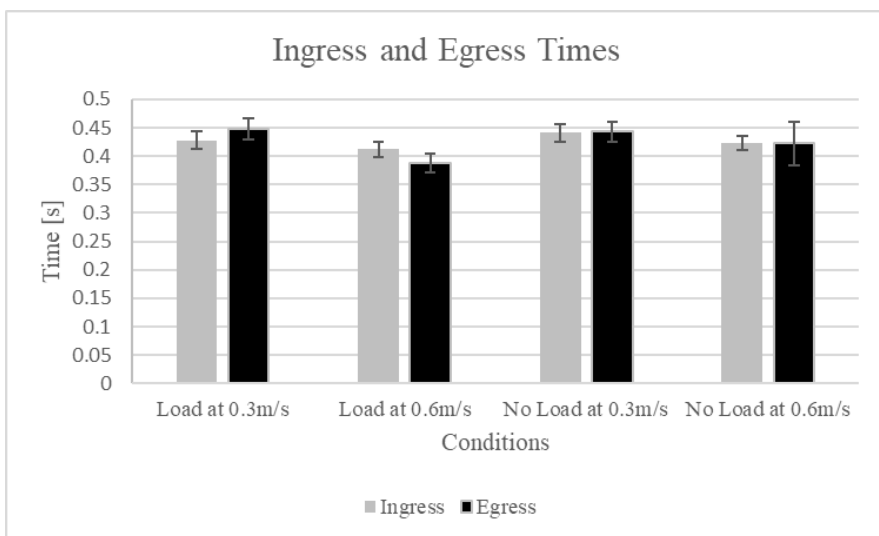

Figure 2. Ingress and Egress times taken by first and last step, error bars represent standard error to mean.

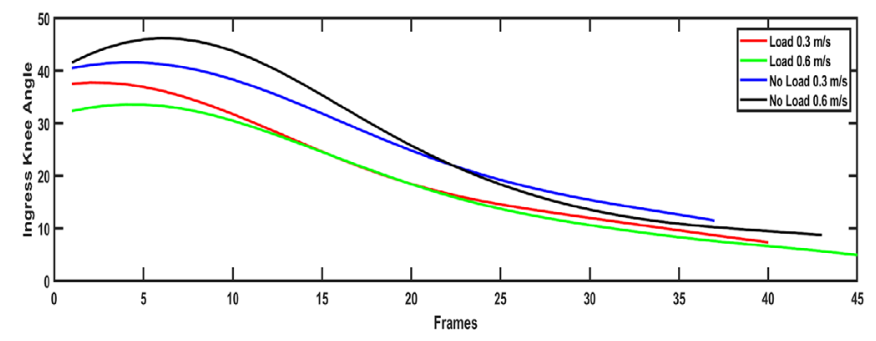

Figure 3. Knee angle at ingress with and without load at 0.3 $\mathrm{m} / \mathrm{s}$ and $0.6 \mathrm{~m} / \mathrm{s}$

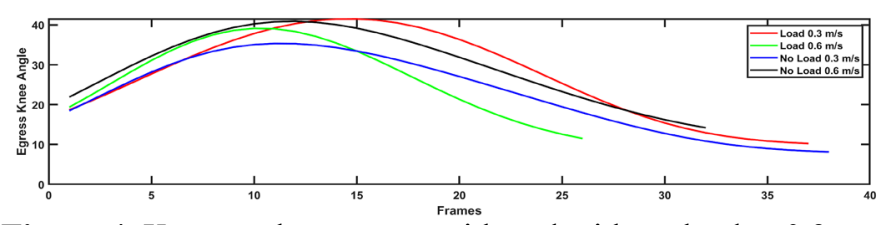

Figure 4. Knee angle at egress with and without load at 0.3 $\mathrm{m} / \mathrm{s}$ and $0.6 \mathrm{~m} / \mathrm{s}$

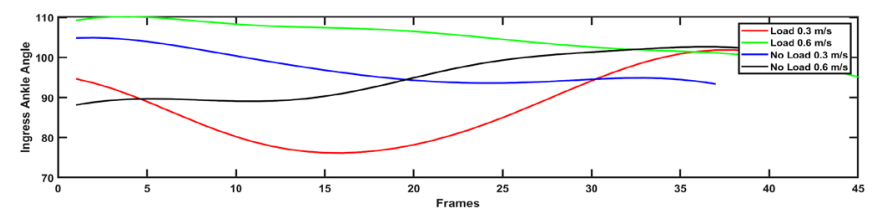

Figure 5. Ankle angle at ingress with and without load at 0.3 $\mathrm{m} / \mathrm{s}$ and $0.6 \mathrm{~m} / \mathrm{s}$

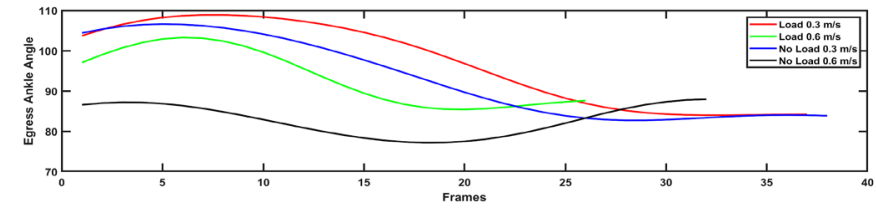

Figure 6. Ankle angle at egress with and without load at 0.3 $\mathrm{m} / \mathrm{s}$ and $0.6 \mathrm{~m} / \mathrm{s}$

Discussion

Travelators are primarily present indoors, in highly populated environments that require fast paced movement within the facility. Of popular locations, travelators are consistently found in airports, where many people carry bags or backpacks. The purpose of this study was to evaluate the relative safety of individuals carrying different loads, measured by variations in 
gait kinematics, on travelators operating at different speeds. The fixed variables controlled in this study included the operating speed of the travelator $(0.3 \mathrm{~m} / \mathrm{s}$ and $0.6 \mathrm{~m} / \mathrm{s})$ and the amount of load the passenger was carrying in a traditionally strapped backpack (no load and 10\% body weight). These variables mimicked travelers' common environmental conditions of travelators.

Due to small sample size no statistically significant differences were found between ingress and egress time at the two variable speeds of travelators. The lack of significance may be due to several factors. This study was limited to 10 participants, and participants are of younger age, were also more likely to be healthier and stronger than the elderly or those prone to fall risk. However, there was a consistent trend, that at faster speed of the track $(0.6 \mathrm{~m} / \mathrm{s})$ lead to a lower ingress and egress times (Fig. 2). Caderby et al, reported that anticipatory postural adjustments occur before gait initiation, or initial contact(Caderby et al., 2017). The anticipatory postural adjustments help the individual safely transfer load from a stable surface to a moving surface. While stepping onto a fast moving travelator (ingress time), individuals have to increase their speed. Failure to adjust to the fast moving travelator could result in loss of balance and increased fall risk. Ingress time is faster at higher travelator speed because of the individual's adjustment to the speed of the track.

The healthy participants in this study did not have problems with stability and had low fall risk, which is why they were able to adjust to the increased speed of the travelator. It has been shown that elderly individuals as well as individuals with certain disabilities may have difficulty in postural transitions. Shkuratova et al, found that the ability to maintain balance in older subjects was decreased when they were required to walk faster than their preferred speed(Shkuratova, Morris, \& Huxham, 2004). If older individuals find travelator speeds too fast or faster than what they are used to, they may lose balance as they try to adjust their own speed to that of the travelator. Loss of balance may result in a higher fall risk during ingress time. Some other common conditions that are closely connected to aging are hearing loss, reduced bone mineral density (BMD), and sarcopenia.

To represent travelers carrying load, the participants in this study underwent three trials with variable load, namely, no load and $10 \%$ body weight. Ingress and egress time values, as well as ankle and knee angle, were measured as a representative measure to assess stability and fall risk. Fig. 2 shows that ingress time was lower with a load at speeds 0.3 $\mathrm{m} / \mathrm{s}$ and $0.6 \mathrm{~m} / \mathrm{s}$ than it was without a load at the same speeds. This could be partially explained by the fact that participants feel more stable when on double limb support with added weight, participants descend more quickly (shorter single limb stance) from the starting platform onto the track.

A strategy used to understand stability in gait or postural transition is altering gait pattern. Young adults alter their walking patterns before walking onto a moving surface(Hsu, Wang, Lu, \& Lu, 2015).
During gait initiation, the ipsilateral limb comes up off the ground, the knee flexes and this flexion is maintained till the foot contact. Fig. 3 shows the ingress knee angle values over time (half a second or 50 frames). The ingress knee angle at the variables of load at $0.3 \mathrm{~m} / \mathrm{s}$, load at $0.6 \mathrm{~m} / \mathrm{s}$, no load at 0.3 $\mathrm{m} / \mathrm{s}$, and no load at $0.6 \mathrm{~m} / \mathrm{s}$ resulted in a common pattern. The common trend observed was knee flexion being the greatest during toe off (moving from platform to the moving treadmill) and gradually the knee straightening (with remaining flexion) when the foot touches the conveyor belt. Although no significant difference in maximum knee flexion were observed amongst the four conditions but a trend was observed in Fig. 3 . Previous studies have confirmed that while walking on a flat surface(Jandacka et al., 2018), knee flexion increases when carrying a load (backpack)(Ozgul et al., 2012). Greater knee flexion allows a person carrying weight to lower their center of mass thus increasing stability. The opposite results reflected in this study compared to previous studies and can be attributed to small load and a moving surface (treadmill). Carrying a small load does not result in altered gait patterns or compensatory balance responses in healthy adults. One way to elicit the change in gait or compensatory responses is to increase the load to $15 \%$ of the person's body weight. The moving treadmill can also be attributed to the obtained results because participants were asked to step down by 4 inches onto the moving treadmill instead of having them walk into it. If the participants were going to make any compensatory responses, they have done so before stepping onto the treadmill, which is not observed in Fig. 3.

Fig. 4 depicts egress knee angle values over time. The common pattern seen for all four conditions was an increase in knee flexion then the knee extension, thus reducing knee flexion. This pattern is seen because the participants began to prepare to lift their leg off the treadmill and onto the platform. No load condition at speed $0.3 \mathrm{~m} / \mathrm{s}$ had the least amount of knee flexion. This corroborates with previous studies where no load yields lesser knee flexion angles and no compensatory balance is required. Load carriage condition at speed $0.3 \mathrm{~m} / \mathrm{s}$ and no load at $0.6 \mathrm{~m} / \mathrm{s}$ had the highest knee flexion angle at 40 degrees. The condition with load carriage at speed $0.3 \mathrm{~m} / \mathrm{s}$ shows a greater knee flexion in order to compensate for the load being carried. A higher knee flexion angle will allow participants to become stable when lifting the leg from a moving surface and onto a static platform. The condition with no load at $0.6 \mathrm{~m} / \mathrm{s}$ depicts an unusual case with the data showing high knee flexion angle. A greater knee flexion can be a compensatory response to the faster speed of the treadmill. Load at speed $0.6 \mathrm{~m} / \mathrm{s}$ had maximum knee flexion at 38 degrees. Since the data is an average of 10 participants, with everyone utilizing different strategies, less knee flexion is observed compared to load at speed $0.3 \mathrm{~m} / \mathrm{s}$ and no load condition at $0.6 \mathrm{~m} / \mathrm{s}$. Participants utilized great knee flexion in order to stabilize themselves as observed with the conditions with load at speed $0.3 \mathrm{~m} / \mathrm{s}$ and no load at 0.6 $\mathrm{m} / \mathrm{s}$.

As shown in Fig 5, more plantarflexion was observed at the initial movement, than in the other three conditions. The $\sim 110$ degrees of plantarflexion were used in order to compensate for 
the load on the posterior side of the body in the opposite direction of the step down. Stepping out and down (plantarflexing) during ingress farther onto a faster moving surface while utilizing the forefoot area is an attempt to maintain balance conditions that are impacted by the load(Pau, Corona, Leban, \& Pau, 2011). A similar pattern was observed in the condition with no load at the slower speed of 0.3 meters per second. This strategy may have been adopted due to lack of weight and high speed could have influenced more plantarflexion. During the condition with load at the slower speed $(0.3 \mathrm{~m} / \mathrm{s})$, we found large dorsiflexion (Fig. 5). The subjects attempted to maintain or restore balance by using ankle strategy, which is used in conditions of slow perturbation and recruits muscles from distal to proximal. Once stable balance was regained by moving the center of mass over the base of support there was plantarflexion to attain a neutrally positioned ankle. The final ingress condition at higher speed with no load in Fig. 5, exhibits a general trend of plantarflexion. Subjects then utilize hip strategy for maintaining or restoring balance which is used for fast perturbations and in addition lifting heels during the hip flexion, thus creating the plantarflexion shown in Fig. 5.

During the egress shown in Fig. 6, a similar pattern is displayed for both load conditions as well as the slower speed with no load. Beginning from a small plantarflexion movement, all three conditions show rapid dorsiflexion until reaching a neutral position. This is expected, as in the typical gait cycle during swing phase $(\sim 60$ to $80 \%)$, rapid dorsiflexion is also necessary to attain a neutral ankle position and avoid dragging the foot. In addition, since the platform subjects were required to step onto was higher (about 4 inch) than the moving surface, even more dorsiflexion was needed. In the conditions at the faster speed $(0.6 \mathrm{~m} / \mathrm{s})$, the movement needed to be completed more quickly given the rapid approach to the platform that obstructed the pathway. Thus, a quicker completion of the movement is observed. The condition with no load at the higher speed having much more initial dorsiflexion can be attributed to the values being an average of all subjects, which varied in their methods and strategies across all conditions. However, the overall kinematics of the faster speed conditions exhibit the same general trend.

\section{Limitations:}

The most significant limitation encountered in the research was the age and fitness level of subjects. Since the research is steered towards application to the fall-risk in airports and places with moving walkways, the research fails to observe significant changes in healthy individuals under 28 years of age. In addition, the sample size of 10 subjects is relatively small to generalizability. Another limitation being the shoe type, all subjects used athletic type shoes for the trials however the weight, outsole shape, heel height, and insole material are a few of the factors that were unregulated. There have been studies done on the effect of asymmetric loads on gait patterns(Park et al., 2018). We were constrained to using a symmetric load for our study, but perhaps an asymmetric load would be more accurate to practical application (duffel bag, suitcase, etc.). Another limitation that was present in the research was the length of the moving walkway. The treadmill utilized in research is significantly shorter than a typical moving walkway. Due to the shorter length, this gives less time for subjects to assimilate their balancing technique and stresses the need to focus on stepping off the treadmill before reaching the end platform. Unlike the real-world situations where people normally walk into the travelator, the simulated travelator ingress in the study started with a static standing position, but not dynamic walking status.

\section{Conclusion}

Major buildings such as malls and airports have travelators and escalators to allow people to move across the building or travel between floors. However, many people are not able to use these contraptions and must wait in a long line in order to use the elevators because they may worry about falling or lack balance coordination.

To our knowledge, this is one of the first study looking into kinematics of using travelators. We found that ingress time was lower with load at speeds $0.3 \mathrm{~m} / \mathrm{s}$ and $0.6 \mathrm{~m} / \mathrm{s}$ compared to trials with no load at the same speeds. The lack of significance in the data can be attributed to the ten participants being young healthy adults who are far from being in the fall risk population. Knee angles measured for ingress showed high knee flexion for all four variables, with even higher knee flexion when participants carried no load. This was attributed to a low load carried combined with the act of stepping from a platform onto a moving treadmill. Knee angles measured for egress showed high knee flexion when stepping off of the moving treadmill and onto a platform. To conclude, the results of this study propel us into the future of possibilities that could help ergonomic development without risking of the general population.

\section{References}

Caderby, T., Yiou, E., Peyrot, N., de Vivies, X., Bonazzi, B., \& Dalleau, G. (2017). Effects of Changing Body Weight Distribution on Mediolateral Stability Control during Gait Initiation. Front Hum Neurosci, 11, 127. doi:10.3389/fnhum.2017.00127

Frames, C. W., Soangra, R., Lockhart, T. E., Lach, J., Ha, D. S., Roberto, K. A., \& Lieberman, A. (2018). Dynamical Properties of Postural Control in Obese Community-Dwelling Older Adults (dagger). Sensors (Basel), 18(6). doi:10.3390/s18061692

Gialloreti, L. E., \& Marazzi, M. C. (1996). [Risk for falls in the elderly. Role of activities of daily living and of the subjective assessment of health status. A casecontrol study]. Recenti Prog Med, 87(9), 405-411.

Hariton, E., \& Locascio, J. J. (2018). Randomised controlled trials - the gold standard for effectiveness research: Study design: randomised controlled trials. BJOG, 125(13), 1716. doi:10.1111/1471-0528.15199

Hsu, W.-C., Wang, T.-M., Lu, H.-L., \& Lu, T.-W. (2015). Anticipatory changes in control of swing foot and lower limb joints when walking onto a moving surface traveling at constant speed. Gait \& Posture, 41(1), 185-191. doi:10.1016/j.gaitpost.2014.10.003

Jandacka, D., Plesek, J., Skypala, J., Uchytil, J., Silvernail, J. F., \& Hamill, J. (2018). Knee Joint Kinematics and 
Kinetics During Walking and Running After Surgical Achilles Tendon Repair. Orthop J Sports Med, 6(6),

2325967118779862. doi:10.1177/23259671187798662

Lockhart, T. E., Smith, J. L., \& Woldstad, J. C. (2005). Effects

of aging on the biomechanics of slips and falls. Hum

Factors, 47(4), 708-729.

doi:10.1518/001872005775571014

Ozgul, B., Akalan, N. E., Kuchimov, S., Uygur, F., Temelli, Y., \& Polat, M. G. (2012). Effects of unilateral backpack carriage on biomechanics of gait in adolescents: a kinematic analysis. Acta Orthop Traumatol Turc, 46(4), 269-274.

doi:10.3944/aott.2012.2678

Park, K., Sy, J. F., Horn, G. P., Kesler, R. M., Petrucci, M. N., Rosengren, K. S., \& Hsiao-Wecksler, E. T. (2018).

Assessing gait changes in firefighters after

firefighting activities and while carrying asymmetric loads. Appl Ergon, 70, 44-50.

doi:10.1016/j.apergo.2018.01.016

Pau, M., Corona, F., Leban, B., \& Pau, M. (2011). Effects of backpack carriage on foot-ground relationship in children during upright stance. Gait Posture, 33(2), 195-199. doi:10.1016/j.gaitpost.2010.10.096

Sekaran, N. K., Choi, H., Hayward, R. A., \& Langa, K. M. (2013). Fall-associated difficulty with activities of daily living in functionally independent individuals aged 65 to 69 in the United States: a cohort study. $J$ Am Geriatr Soc, 61(1), 96-100. doi:10.1111/jgs.12071

Shkuratova, N., Morris, M. E., \& Huxham, F. (2004). Effects of age on balance control during walking. Arch Phys Med Rehabil, 85(4), 582-588. doi:10.1016/j.apmr.2003.06.021

Walsh, G. S., Low, D. C., \& Arkesteijn, M. (2018). Effect of stable and unstable load carriage on walking gait variability, dynamic stability and muscle activity of older adults. $J$ Biomech, 73, 18-23. doi:10.1016/j.jbiomech.2018.03.018 